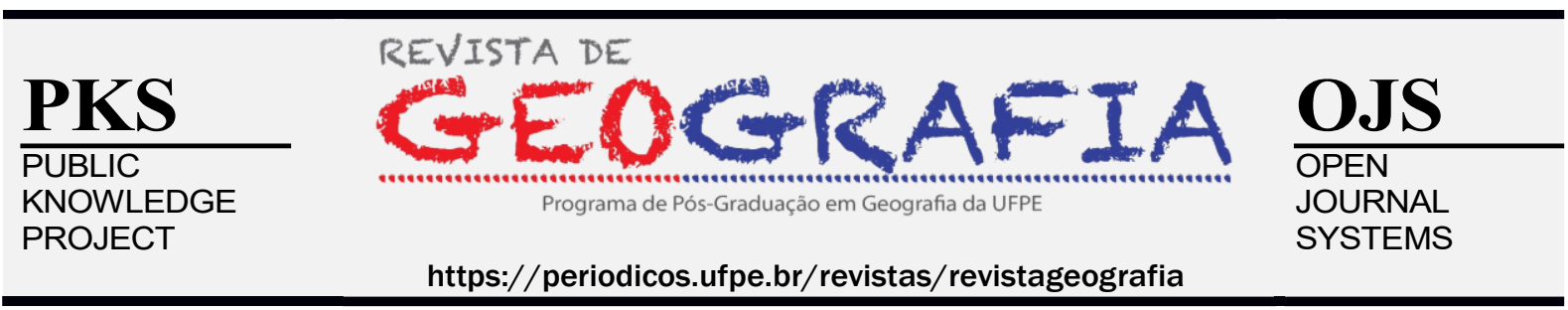

\title{
FITOSSOCIOLOGIA DO ESTRATO HERBÁCEO NA FISIONOMIA FLORESTA DE RESTINGA NO LITORAL SUL DE PERNAMBUCO
}

\author{
Eduardo Bezerra de Almeida Jr. ${ }_{2}^{1}$ Catherine Rios Santos ${ }^{2}$, Murielle Andreo Olivo ${ }^{3}$, Patricia \\ Barbosa Lima ${ }^{4}$, Carmen Sílvia Zickel ${ }^{5}$
}

\begin{abstract}
${ }^{l}$ Dr. em Botânica. Prof. da Universidade Federal do Maranhão, São Luís/MA. Email: ebaj25@yahoo.com.br; http://orcid.org/0000-0001-7517-4775

2 Graduada em Ciências Biológicas. Programa de Pós-graduação em Botânica, Universidade Federal Rural de Pernambuco,Recife/PE.Email: catherineriosantos@gmail.com; https://orcid.org/0000-0003-1580-3765

3 Bióloga e professora da Educação básica. Universidade Federal Rural de Pernambuco. Email: murielleolivo@hotmail.com; https://orcid.org/0000-0002-2703-2999

${ }^{4}$ Dra. em Botânica. Departamento de Biologia, Área de Botânica, Universidade Federal Rural de Pernambuco, Recife/PE. Email: patriciablima@gmail.com; https://orcid.org/0000-0002-8743-333X

5 Dra. em Botânica. Profa. da Universidade Federal Rural de Pernambuco, Recife/PE. Email: zickelbr@yahoo.com.br; https://orcid.org/0000-0002-1323-4717
\end{abstract}

Artigo recebido em 12/07/2020 e aceito em 17/05/2021

\begin{abstract}
RESUMO
O objetivo do estudo foi caracterizar a estrutura herbácea na fisionomia floresta da restinga da RPPN de Maracaípe, PE, Nordeste do Brasil. Os dados fitossociológicos foram obtidos através de 50 parcelas $(1 \times 1 \mathrm{~m})$, distribuídas em cinco transectos $(100 \mathrm{~m}$ cada) paralelos, alocadas na fisionomia. Os indivíduos herbáceos foram analisados e tiveram os parâmetros calculados, além do índice de diversidade de Shannon. Registraram-se 13 espécies, sendo três permanecendo como morfoespécies, distribuídas em nove gêneros e sete famílias, contabilizando um total de 141 indivíduos. As famílias mais representativas foram Araceae, Rubiaceae e Euphorbiaceae. As espécies de maior VI foram Stigmaphyllon paralias, Anthurium affine e Phyllodendron imbe. Os índices de diversidade de Shannon (H') e equabilidade de Pielou (J') apresentaram os valores de 1,384 e 0,540, respectivamente.
\end{abstract}

Palavras-chave: diversidade; fitossociologia; vegetação costeira; Nordeste do Brasil.

\section{PHYTOSOCIOLOGY OF HERBACEOUS LAYER IN RESTINGA FOREST PHYSIOGNOMY IN THE SOUTHERN COAST OF PERNAMBUCO STATE}

\begin{abstract}
The objective of the study was to characterize the herbaceous structure in the forest physiognomy of the RPPN restinga of Maracaípe, PE, Northeast Brazil. The phytosociological sampling were obtained through 50 plots $(1 \times 1 \mathrm{~m})$, distributed in five parallel transects $(100 \mathrm{~m}$ each), allocated in each physiognomy. The herbaceous individuals were analyzed and had the parameters calculated, in addition to the Shannon diversity index. Thirteen species were registered, three remaining as morphospecies, distributed in nine genera and seven families, totaling 141 individuals. The most representative families
\end{abstract}


were Araceae, Rubiaceae and Euphorbiaceae. The species with the highest VI were Stigmaphyllon paralias, Anthurium affine and Phyllodendron imbe. The diversity indexes of Shannon ( $\left.\mathrm{H}^{\prime}\right)$ and Pielou equability $\left(\mathrm{J}^{\prime}\right)$ presented values of 1.384 and 0.540 , respectively

Keywords: diversity; phytosociology; coastal vegetation; Northeast of Brazil.

\section{INTRODUÇÃO}

A restinga é considerada um ecossistema litorâneo formado em solos arenosos datados do período Quaternário. A vegetação apresenta fisionomias típicas, no qual são encontradas predominantemente plantas herbáceas, algumas áreas com formações arbustivas, além de fisionomias mais fechadas classificadas como florestas (SANTOS-FILHO et al., 2010). O arranjo da estrutura vegetal dessas áreas e o desenvolvimento das comunidades de plantas são influenciados por fatores edáficos, climáticos, relacionados a umidade e a flora de outros ecossistemas, sendo necessários constantes estudos que analisem a composição das espécies vegetais da restinga (SANTOS-FILHO et al., 2015; SILVA e MELO JR., 2017).

Dentre os estratos da vegetação de restinga, as herbáceas são conhecidas como pioneiras por seu rápido crescimento e suas estratégias de se estabelecer no ambiente. Sendo importantes para a manutenção dos ecossistemas por contribuírem como alimento para herbívoros, por formarem microhabitats para outros seres vivos e auxiliarem na ciclagem de nutrientes e dispersão dos frutos. Além disso, a composição herbácea pode contribuir com $33 \%$ a $52 \%$ da riqueza específica da flora de uma área (GENTRY e DODSON, 1987; SOARES JR. et al., 2008).

Normalmente, as restingas apresentam uma alta riqueza de espécies herbáceas, porém não são todas que possuem características peculiares para fixação e estabelecimento nesse ambiente (MELO JR. e BOEGER, 2015). Com isso, essas plantas se instalam sobre as dunas e restinga em fase inicial de regeneração, modificam as condições iniciais do ambiente e permitem a entrada, crescimento e o estabelecimento de outras plantas, favorecendo a diversidade vegetal (SANTOS et al., 2000). Apesar da sua contribuição com a riqueza de uma floresta, as variações microclimáticas (DIDHAM e LAWTON, 1999) e alterações biológicas podem comprometer o sucesso reprodutivo desse estrato (HONNAY et al., 2005; BRUNA, 2002; URIARTE et al., 2010) podendo alterar a diversidade dessa comunidade vegetal (YADAV e GUPTA, 2007).

O conhecimento da composição florística e estrutural do estrato herbáceo de áreas florestais permite inferir sobre as condições ambientais e os estágios de conservação dos ecossistemas (CITADINI-ZANETTE, 1984; CITADINI-ZANETTE e BAPTISTA, 1989; MEIRA-NETO e MARTINS, 2003). Nesse contexto, a composição herbácea pode fornecer 
respostas mais rápidas às mudanças ambientais (GIVNISH, 1986; CHAGAS et al., 2010), tornando esse estrato importante para as análises dos ecossistemas.

No interior da floresta, as herbáceas distribuem-se de acordo com as condições edáficas, microclimáticas e distribuição da luminosidade (MEIRA-NETO et al., 2005). Com isso, observa-se que esse grupo recebe influência do estrato lenhoso devido à cobertura proporcionada pelas árvores e arbustos, diminuindo a incidência luminosa na porção inferior florestal (MARASCHIN-SILVA et al., 2009), e consequentemente tendo uma menor densidade de ervas sob a cobertura arbórea (ANDRADE, 1992).

Nesse contexto, analisar a flora herbácea das áreas de restinga do Nordeste possibilita ampliar os registros das plantas que ocorrem no litoral e assim contribuir para a compreensão da dinâmica florestal e manutenção da biodiversidade. Portanto, o presente estudo teve como objetivo caracterizar a estrutura do estrato herbáceo da fisionomia floresta de uma área de restinga do litoral sul de Pernambuco, Nordeste do Brasil.

\section{MATERIAL E MÉTODOS}

Área de estudo

O estudo foi realizado na Reserva Particular do Patrimônio Natural (RPPN) Nossa Senhora do Outeiro de Maracaípe, localizada no município de Ipojuca (08³1'48's e $35^{\circ} 01^{\prime} 05^{\prime}$ 'W), litoral sul de Pernambuco (Figura 1). A RPPN ocupa uma área de cerca de 130ha, dos quais 76,2 ha que se constituem das fisionomias campo não inundável, campo inundável e floresta não inundável de restinga (ALMEIDA JR. et al., 2009). 


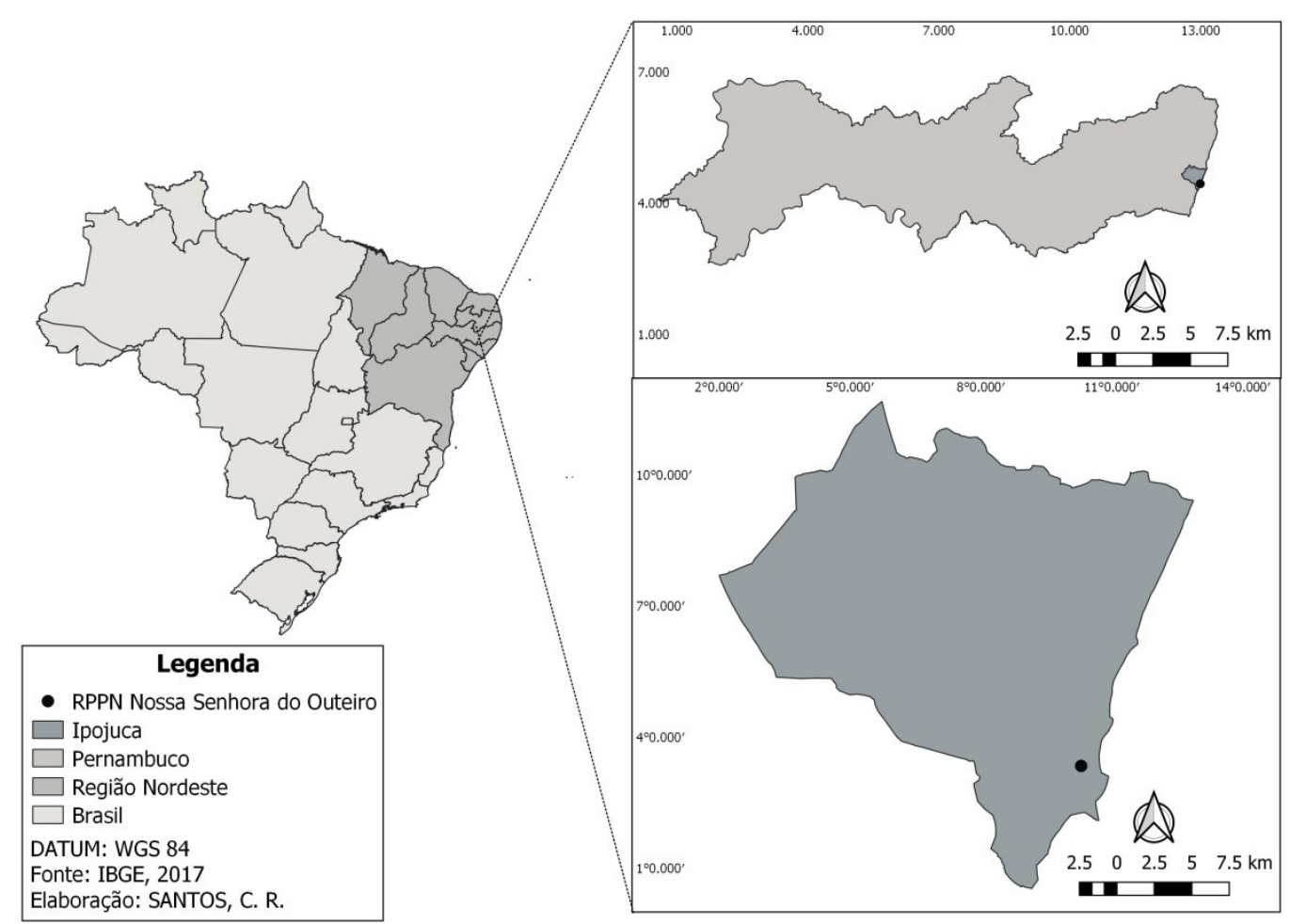

Figura 1: Mapa da região Nordeste evidenciando a localização da restinga da RPPN de Maracaípe, Ipojuca, Pernambuco. Fonte: Santos, R.C.

O clima local é classificado como As' (tropical chuvoso com verão seco), evidenciando menos de $60 \mathrm{~mm}$ de chuva no mês mais seco (KOEPPEN, 1948) e precipitação anual média de $2.533 \mathrm{~mm}$ (INMET, 2015). O solo é do tipo arenoso, com teores de areia variando de $98 \%$ a 100\% (ALMEIDA JR. et al., 2009), sendo classificado como Neossolo Quartzarênico (EMBRAPA, 1999).

\section{Coleta e amostragem do estrato herbáceo}

A amostragem fitossociológica da composição herbácea foi realizada no período de agosto de 2004 e janeiro de 2005 a partir do método de parcelas Mueller-Dombois e Ellenberg (1974) na fisionomia de floresta. As parcelas foram distribuídas ao longo de cinco transectos (100 m cada) com distância de 10m e paralelos entre si. Em cada transecto foram alocadas parcelas de $1 \mathrm{~m}^{2}$ (a esquerda ou direita de acordo com sorteio prévio) totalizando 50 parcelas para a amostragem.

Foram consideradas como pertencentes do estrato herbáceo as plantas de caule verde que não apresentassem lignificação na extensão do caule (ARAÚJO et al., 2005; ANDRADE et al., 2009) e que possuíssem altura entre 0,15 e $1 \mathrm{~m}$ e diâmetro entre 0,1 a $10 \mathrm{~cm}$ (TOREZAN, 1995). O limite mínimo de altura foi incluído para evitar possíveis registros de plântulas e, 
consequentemente, erros na identificação das espécies. Os indivíduos jovens das espécies arbóreas não foram considerados para essa amostragem.

Foi considerado como único indivíduo a planta que não apresentava conexão com outro indivíduo à altura do solo. Todos os indivíduos amostrados nas parcelas que atendiam ao critério estabelecido tinham sua altura e diâmetro mensurados, sendo coletados para posterior identificação (no menor nível hierárquico possível). Também foram classificadas quanto às formas de vida, seguindo a proposta de Raunkiaer (1934), adaptadas por Mueller-Dombois e Ellenberg (1974).

A partir dos dados obtidos foram estimados os parâmetros fitossociológicos: densidade (absoluta e relativa), frequência (absoluta e relativa), valor de Importância (VI), valor de Cobertura (VC), Índice de Diversidade de Shannon (H') e Índice de Equabilidade de Pielou (J'), todos calculados utilizando-se o pacote FITOPAC 2.1 (SHEPHERD, 2006). Os valores referentes à densidade, frequência e dominância foram utilizados para determinar o VI, e a partir da soma da densidade relativa e dominância relativa foi obtido o VC. Para a caracterização da comunidade amostrada foram elaborados histogramas do número de indivíduos por intervalos de altura (amplitude de $10 \mathrm{~cm}$ ).

A coleta do material botânico seguiu a metodologia indicada por Peixoto e Maia (2013). As espécies foram identificadas a partir de bibliografia especializada, chaves de identificação e por comparação do material depositado nos herbários de Pernambuco. Os exemplares que apresentaram dificuldade quanto à identificação ou que necessitavam de confirmação foram enviados a especialistas. As espécies foram listadas seguindo o sistema de classificação do APG IV (2016) e a verificação da grafia das espécies e dos autores, assim como sua distribuição geográfica, foi realizada através do site da Flora do Brasil 2020 (http://floradobrasil.jbrj.gov. br), The Plant List (http://www.theplantlist.org); e Tropicos (http://www. tropicos.org). Para o padrão de distribuição geográfica foram consideradas apenas as espécies identificadas até epiteto específico. As exsicatas originadas foram incorporadas ao acervo do Herbário Vasconcelos Sobrinho (PEUFR), da Universidade Federal Rural de Pernambuco, e no Herbário Dárdano de Andrade Lima (IPA), do Instituto de Pesquisa Agropecuária.

\section{RESULTADOS}

$\mathrm{Na}$ amostragem realizada na fisionomia floresta foram identificadas 13 espécies, sendo três mantidas em morfoespécies, distribuídas em nove gêneros e sete famílias (Tabela 1), contabilizando um total de 141 indivíduos. As famílias com maior representatividade em 
relação ao número de espécies foram Araceae, Euphorbiaceae e Rubiaceae, apresentando duas espécies, cada. Juntas, essas famílias correspondem a $46 \%$ do total de espécies amostradas.

Quanto a classificação das formas de vida, foi demonstrado que as espécies pertencem, em sua maioria, às terófitas $(30,8 \%)$, caméfitas (23\%) e nanofanerófitas $(15,4 \%)$ (Tabela 1$)$. As espécies possuem ampla distribuição no Brasil e dentre estas espécies, quatro são endêmicas do Brasil (Stigmaphyllon paralias, Croton sellowii, Anthurium affine e Philodendron imbe) e duas características de áreas antrópicas (Staelia virgata e Croton glandulosus). A espécie Solanum pseudoquina possui distribuição restrita ao bioma da Mata Atlântica.

As espécies com maior valor de importância (VI) foram Stigmaphyllon paralias, Anthurium affine e Philodendron imbe. As três espécies de maior VI também apresentaram maior frequência (Tabela 1). Os índices de diversidade de Shannon (H') foi de 1,384 nat.ind ${ }^{-1}$ e o de equabilidade de Pielou (J') foi de 0,540.

A altura média dos indivíduos amostrados foi de $30 \mathrm{~cm}$, formando um estrato menos denso em alguns trechos da fisionomia floresta; a altura máxima foi de $96 \mathrm{~cm}$, representada por Stigmaphyllon paralias, e altura mínima de $15 \mathrm{~cm}$ com destaque para Croton glandulosus, Stigmaphyllon paralias e Oceocladis maculata. A distribuição do número de indivíduos por classes de altura evidenciou que cerca de $60 \%$ dos registros apresentaram até $35 \mathrm{~cm}$ (Figura 2). 
Tabela 1: Lista das espécies do estrato herbáceo amostradas na fisionomia floresta da restinga da RPPN de Maracaípe, Ipojuca, Pernambuco. NInd = Número de Indivíduos; FrAbs = Frequência Absoluta; FrRel = Frequência Relativa; DeAbs = Densidade Absoluta; DeRel $=$ Densidade Relativa; VI = Valor de Importância; VC = Valor de Cobertura. Formas de Vida = V.F.: NaFan - nanofanerófito; Cam - caméfito; Ter - terófito; Crp - criptófito; Hmc - hemicriptófito; Trp - trepadeira.

\begin{tabular}{|c|c|c|c|c|c|c|c|c|c|c|}
\hline Espécies & Famílias & Distribuição & F.V. & NInd & FrAbs & FrRel & DeAbs & DeRel & VI & $\mathrm{VC}$ \\
\hline Stigmaphyllon paralias A. Juss. & Malpighiaceae & Ampla & NaFan & 90 & 20,83 & 25,64 & 18750 & 54,88 & 151,3 & 125,66 \\
\hline Anthurium affine Schott & Araceae & Ampla & Hmc & 14 & 18,75 & 23,08 & 2916,7 & 8,54 & 43,79 & 20,71 \\
\hline Philodendron imbe Schott ex Kunth. & Araceae & Ampla & Trp & 4 & 8,33 & 10,26 & 833,3 & 2,44 & 16,82 & 6,57 \\
\hline Morfoespécie 3 & - & - & Ter & 5 & 6,25 & 7,69 & 1041,7 & 3,05 & 13,3 & 5,61 \\
\hline $\begin{array}{l}\text { Staelia virgata (Link ex Roem. e Schult.) } \\
\text { K.Schum. }\end{array}$ & Rubiaceae & Ampla & Cam & 4 & 6,25 & 7,69 & 833,3 & 2,44 & 11,81 & 4,12 \\
\hline Croton glandulosus L. & Euphorbiaceae & Ampla & Cam & 5 & 4,17 & 5,13 & 1041,7 & 3,05 & 9,56 & 4,43 \\
\hline Rugoloa pilosa (Sw.) Zuloaga & Poaceae & Ampla & Crp & 7 & 2,08 & 2,56 & 1458,3 & 4,27 & 8,88 & 6,31 \\
\hline Morfoespécie 1 & - & - & Ter & 2 & 4,17 & 5,13 & 416,7 & 1,22 & 6,64 & 1,51 \\
\hline Solanum pseudoquina A.St.-Hil. & Solanaceae & Restrita & Cam & 3 & 2,08 & 2,56 & 625 & 1,83 & 5,74 & 3,17 \\
\hline Psychotria bahiensis DC. & Rubiaceae & Ampla & NaFan & 1 & 2,08 & 2,56 & 208,3 & 0,61 & 5,71 & 3,15 \\
\hline Oeceoclades maculata (Lindl.) Lindl. & Orchidaceae & Ampla & Ter & 3 & 2,08 & 2,56 & 625 & 1,83 & 4,96 & 2,39 \\
\hline Croton sellowii Baill. & Euphorbiaceae & Ampla & Cam & 2 & 2,08 & 2,56 & 416,7 & 1,22 & 4,2 & 1,63 \\
\hline Morfoespécie 2 & - & & Ter & 1 & 2,08 & 2,56 & 208,3 & 0,61 & 3,29 & 0,72 \\
\hline
\end{tabular}

\begin{tabular}{llc}
\hline 2020 & ISSN 0104-5490 & 88
\end{tabular}




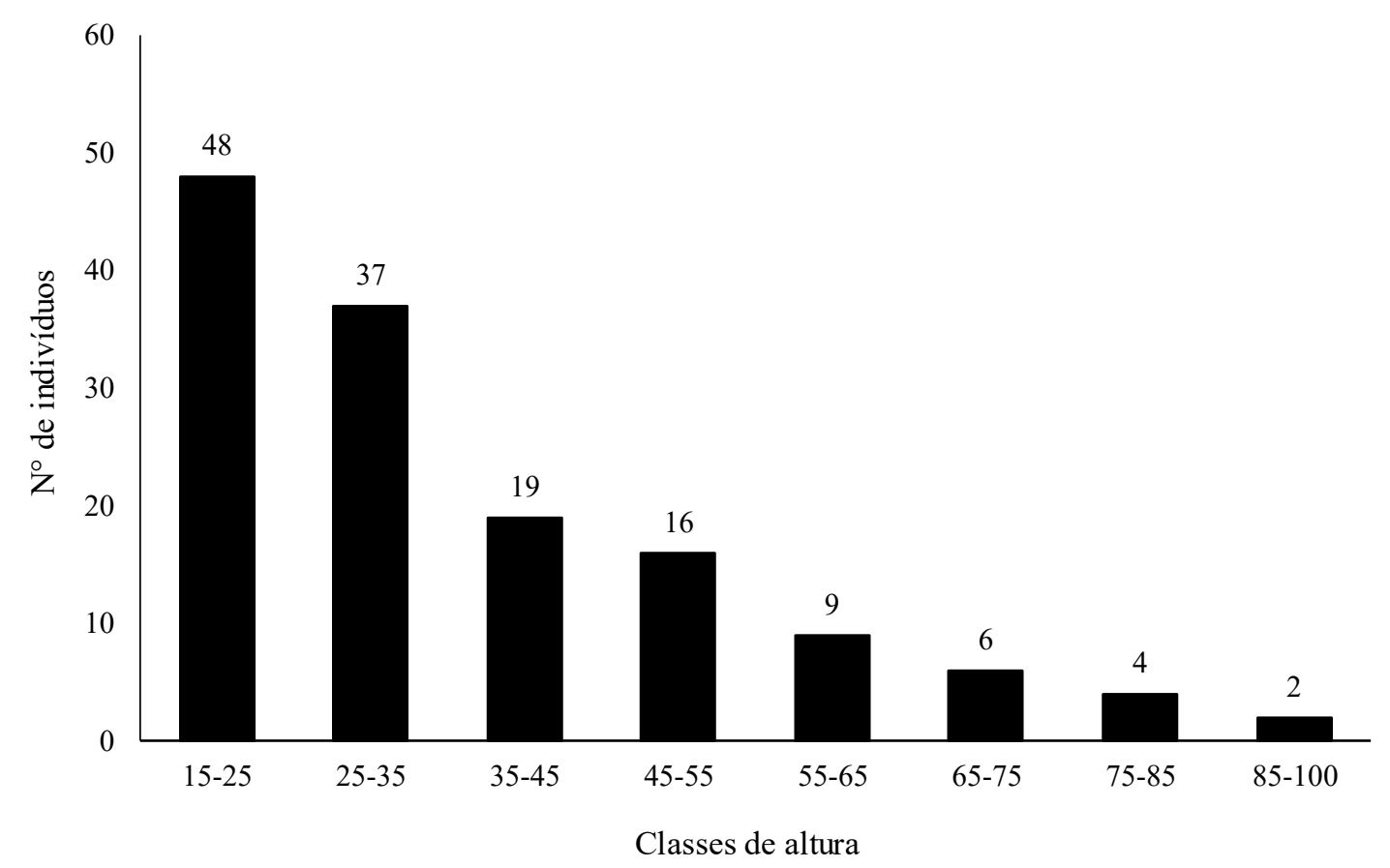

Figura 2: Distribuição de frequência em classes de altura a intervalos de $10 \mathrm{~cm}$ das espécies herbáceas amostradas, em estrato herbáceo da fisionomia florestal de restinga da RPPN de Maracaípe, Ipojuca, Pernambuco.

\section{DISCUSSÃ̃O}

No estudo florístico realizado por Almeida Jr. et al. (2009) foram consideradas todas as fitofisionomias da RPPN de Maracaípe, e as famílias Rubiaceae e Euphorbiaceae foram listadas entre as mais representativas para a área. Cabe destacar que estudos sobre o arranjo estrutural herbáceo em fisionomias de florestas de restinga ainda são escassos na região Nordeste do país; impossibilitando, de certa forma, que algumas análises sejam realizadas.

Apesar de ser em um ambiente diferente em relação à área do presente estudo, Muller e Waechter (2001) também destacaram a família Rubiaceae como a mais representativa do componente herbáceo em uma floresta costeira no Rio Grande do Sul. Já a família Euphorbiaceae apresentou maior riqueza na restinga no litoral de Pernambuco com as espécies Croton sellowii e Croton glandulosus, consideradas como pioneiras por contribuírem com o estabelecimento de outras espécies devido à proteção do solo (SACRAMENTO et al., 2007). Segundo Menezes et al. (2012) C. sellowii é uma espécie ruderal que pode ser indicadora de ambiente degradado. No presente estudo, porém, essa espécie juntamente com C. glandulosos, apresentaram baixos valores em relação aos parâmetros estruturais, o que pode ser um indicativo de pouco indício degradação ambiental. 
No presente estudo, as espécies consideradas endêmicas foram as que apresentaram maior VI. E o desenvolvimento dessas espécies na restinga pode ser justificado pela proximidade de fragmentos de floresta Atlântica, por exemplo, que contribuiu com a colonização de várias espécies na costa litorânea (CERQUEIRA, 2000). A família Araceae destaca-se por ter duas espécies com maior VI. Essa família possui alta diversidade na Mata Atlântica, o que pode justificar a representatividade da família no presente estudo. Tendo em vista que a vegetação costeira do litoral pernambucano recebe influência deste Bioma (PONTES e ALVES, 2011).

As espécies Stigmaphyllon paralias e Anthurium affine apresentam ampla distribuição e ocorrem em ambiente como Mata Atlântica, Cerrado e Caatinga; além das restingas ao longo litoral do Nordeste brasileiro. S. paralias também possui alta representatividade em número de indivíduos, podendo ser registrado em fisionomias distintas (como campo, fruticeto e floresta) (SILVA et al., 2008). Todavia, cabem algumas observações em relação a Stigmaphyllon paralias. Apesar dessa espécie possuir o maior VI na restinga do presente estudo, os valores devem ser interpretados com cautela devido ao crescimento clonal e por essa espécie se desenvolver em moitas (PEREIRA et al., 2004; ALMEIDA JR. et al., 2009), o que pode superestimar os valores dos parâmetros estruturais analisados (observação dos autores). Espécies que possuem este padrão de distribuição podem habitar galerias de cerrado que funcionam como corredores ecológicos para a colonização de outros biomas (ASSIS et al., 2004). Já a espécie Solanum pseudoquina foi considerada rara devido à baixa representação na área (sensu MARTINS, 1991) e por ser restrita a Mata Atlântica.

A vegetação lenhosa da área favoreceu o desenvolvimento das espécies Anthurium affine e Philodendron imbe devido ao sombreamento (SACRAMENTO et al., 2007). Os gêneros Anthurium e Philodendron dispõem de estágio reprodutivo ao longo do ano todo, possuem estruturas com cores chamativas e frutos dispersos por pássaros (PONTES e ALVES, 2011), contribuindo para o sucesso reprodutivo.

Em relação às formas de vida observadas para o estrato herbáceo, registrou-se o predomínio de terófitas e caméfitas (Tabela 1). Melo Jr. e Boeger (2015) ao analisar a vegetação de herbáceas em dunas pós-praia, também destacaram as espécies de caméfitas por possuírem condições que favorecem a sua colonização em ambientes litorâneos. As nanofenerófitas ocuparam a terceira posição no ranking, devido à maior expressividade de Stigmaphyllon paralias sendo uma planta comum na comunidade herbácea que se desenvolve em diversas 
feições fisionômicas (SILVA et al., 2008), mas que apresentou grande representação na fisionomia floresta.

Quanto à densidade de indivíduos herbáceos, observou-se um padrão já relatado na literatura para outros ambientes florestais, no qual poucas espécies se destacam devido a maior quantidade de indivíduos (BENÍTEZ-MALVIDO e MARTÍNEZ-RAMOS, 2003). Essa dominância de poucas espécies caracteriza uma estrutura oligárquica (PEREIRA et al., 2004) no qual o estrato herbáceo da restinga de Maracaípe está inserido, visto que algumas espécies tolerantes as condições extremas, como observado nas restingas, gera condições para o estabelecimento de outras espécies mais exigentes (SCARANO, 2002; 2009).

Diante desse contexto, foi registrado um baixo índice de diversidade devido aos fatores comuns aos solos das restingas, como acidez, alto teor de areia e uma distribuição desigual dos nutrientes (SANTOS-FILHO et al., 2013). Além disso, as plantas herbáceas das restingas, comumente, desenvolve-se sob alta incidência luminosa, salinidade e fortes ventos, o que pode influenciar a dominância ecológica de algumas espécies (MACHADO e ALMEIDA JR., 2019).

\section{CONCLUSÃO}

Diante dos dados apresentados, pode-se concluir que as condições ambientais consideradas extremas no que se concerne à escassez de nutrientes, alta luminosidade e acidez do solo podem ser consideradas como fatores limitantes para a diversidade do estrato herbáceo. Cabendo o destaque para o conjunto de espécies terófitas e caméfitas que contribuíram com a cobertura e colonização das áreas.

As espécies Anthurium affine, Philodendron imbe e Stigmaphyllon paralias destacaramse no arranjo estrutural da fisionomia floresta devido a sua forma de crescimento, estratégias de reprodução e interação com as espécies lenhosas na área. Dessa forma, deve ser ampliado o desenvolvimento de estudos ecológicos nas dunas e restingas para que se possa apontar possíveis afinidades entre espécies ou grupos de espécies no arranjo da comunidade vegetal.

\section{AGRADECIMENTOS}

Ao CNPq, pela concessão das bolsas e financiamento do projeto "Aspectos Florísticos, Anatômicos e Ecológicos da vegetação da Restinga da RPPN Nossa Senhora do Outeiro de Maracaípe, Ipojuca, Pernambuco" (proc. 473974/03-2), coordenado pela Profa. Dra. Carmen Silvia Zickel; aos especialistas das famílias que confirmaram parte do material. 


\section{REFERÊNCIAS}

ALMEIDA JR., E.B.; OLIVO, M.A.; ARAÚJO, E.L.; ZICKEL, C.S. Caracterização da vegetação de restinga da RPPN de Maracaípe, Pernambuco, com base na fisionomia, flora, nutrientes do solo e lençol freático. Acta Botanica Brasilica, v. 23, n. 1, p. 36-48. 2009.

ANDRADE, P.M. Estrutura do estrato herbáceo de trechos da Reserva Biológica Mata do Jambeiro, Nova Lima, MG. Dissertação 99 f., Universidade Estadual de Campinas, Campinas. 1992.

ANDRADE, M.V.M.; ANDRADE, A.P.; SILVA, D.S.; BRUNO, R.L.A.; GUEDES, D.S. Levantamento florístico e estrutura fitossociológica do estrato herbáceo e subarbustivo em áreas de caatinga no cariri paraibano. Revista Caatinga, v. 22, n. 1, p. 229-237. 2009.

ARAÚJO, E.L.; SILVA, K.A.; FERRAZ, A.M.N.; SAMPAIO, E.V.S.B.; SILVA, S.I. Diversidade de herbáceas em microhabitats rochoso, plano e ciliar em uma área de caatinga, Caruaru, PE, Brasil. Acta Botânica Brasílica, v. 19, n. 2, p. 285-294. 2005.

ASSIS, A.M.; THOMAS, L.D.; PEREIRA, O.J. Florística de um trecho de floresta de restinga no município de Guarapari, Espírito Santo, Brasil. Acta Botanica Brasilica, v. 18, n. 1, p. 191201. 2004.

APG IV. An update of the Angiosperm Phylogeny Group classification for the orders and families of flowering plants: APG IV. Botanical Journal of the Linnean Society, v. 181, n. 1, p. 1-20. 2016.

BENÍTEZ-MALVIDO, J.; MARTÍNEZ-RAMOS, M. Impact of forest fragmentation on understory plant species richness in Amazonia. Conservation Biology, v. 17, n. 2, p. 389-400. 2003.

BRUNA, E.M. Effects of forest fragmentation on Heliconia acuminata seedling recruitment in central Amazonia. Oecologia, v. 132, p. 235-243. 2002.

CERQUEIRA, R. Biogeografia de Restingas. Ecologia de Restinga e lagoas costeiras. Rio de Janeiro. NUPEM/UFRJ. 12p. 2000.

CHAGAS, M.G.S.; ALMEIDA JR., E.B.; PIMENTEL, R.M.M. Tipos funcionais vegetais em comunidade herbácea costeira da praia de Boa Viagem, Recife, Pernambuco, Brasil. Revista Brasileira de Geografia Física, v. 3, n. 2, p. 96-104. 2010.

CITADINI-ZANETTE, V. Composição florística e fitossociologia da vegetação herbácea terrícola de uma mata de Torres, Rio Grande do Sul, Brasil. Iheringia, série Botânica, v. 32, p. 23-62. 1984.

CITADINI-ZANETTE, V.; BAPTISTA, L.R.M. Vegetação herbácea terrícola de uma comunidade florestal em Limoeiro, município de Torres, Rio Grande do Sul, Brasil. Bol. Inst. Biociências, v. 45, p. 1-8. 1989. 
DIDHAM, R.K.; LAWTON, J.H. Edge structure determines the magnitude of changes in microclimate and vegetation structure in trpical forest fragments. Biotropica, v. 31, p. 17-30. 1999.

EMBRAPA. Sistema brasileiro de classificação de solos. Rio de janeiro, Empresa Brasileira de Pesquisa Agropecuária, Centro Nacional de Pesquisa de Solos. 1999.

GENTRY, A.H.; DODSON, C. Contribuition of nontrees to species richness of a tropical rain forest. Biotropica, v. 19, p. 149-156. 1987.

GIVNISH, T.J. Biomechanical constraints on crown geometry in forest herbs. In On the economy of plant form and function (T.J. Givnish, ed.). Cambridge University Press, New York, p. 525-583. 1986.

HONNAY, O.; JACQUEMYN, H.; BOSSUYT, B.; HERMY, M. Forest fragmentation effects on patch occupancy and population viability of herbaceous plant species. New Phytologist, v. 166, p. 723-736. 2005.

INMET - Instituto Nacional de Meteorologia. Disponível em www.inmet.gov.br (Acessado em: 08/06/2019). 2005.

KOPPEN, W. Climatologia: com un estudio de los climas de la tierra. Mexico, Fondo de Cultura Economica. 1948.

MACHADO, M.A.; ALMEIDA JR., E.B. Spatial structure, diversity, and edaphic factors of an area of Amazonian coast vegetation in Brazil1. Journal of the Torrey Botanical Society, v. 146, n. 1, p. 58-68. 2019.

MARTINS, F.R. Estrutura de uma floresta mesófila. Campinas: Editora da Universidade Estadual de Campinas. 246p. 1991.

MEIRA-NETO, J.A.A.; MARTINS, F.R. Estrutura do sub-bosque herbáceo-arbustivo da mata da silvicultura, uma Floresta Estacional Semidecidual no município de Viçosa, MG. Revista Árvore, v. 27, n. 4, p. 459-471. 2003.

MEIRA-NETO, J.A.; SOUZA, A.L.; LANA, J.M.; VALENTE, G.E. Composição florística, espectro biológico e fitofisionomia da vegetação de muçununga nos municípios de Caravelas e Mucuri, Bahia. Revista Árvore, v. 29, p. 139-150. 2005.

MELO JUNIOR, J.C.F.; BOEGER, M.R.T. Riqueza e estrutura de uma comunidade vegetal de dunas na planície costeira de Santa Catarina. Iheringia, série Botânica, v. 73, n. 3, p. 290-297. 2018.

MENEZES, C.M.; SANTANA, F.D.; SILVA, V.S.A.; SILVA, V.I.S.; ARAUJO, D.S.S. Florística e fitossociologia em um trecho de restinga no Litoral Norte do Estado da Bahia.

Biotemas, v. 25, n. 1, p. 31-38. 2012. 
TROPICOS - Missouri Botanical Garden. Tropicos.org. Disponível em: http://www.tropicos. org. Acesso Dez 2019. 2020.

PEIXOTO, A.L.; MAIA, L.C. Manual de procedimentos para herbários: INCT-Herbário virtual para a Flora e os Fungos. $1^{\mathrm{a}}$ ed. Recife: Editora Universitária UFPE. 2013.

PEREIRA, M.C.A.; CORDEIRO, S.Z.; ARAUJO, D.S.D. Estrutura do estrato herbáceo na formação aberta de Clusia do Parque Nacional da Restinga de Jurubatiba, RJ, Brasil. Acta Botanica Brasilica, v. 18, n. 3, p. 677-687. 2004.

PONTES, T.A.; ALVES, M. Padrões de distribuição geográfica das espécies de Araceae ocorrentes em fragmentos de floresta atlântica em Pernambuco, Brasil. Revista Brasileira de Biociências, v. 9, n. 4, p. 444-454. 2011.

RAUNKIAER, C. The Life Forms of Plants and Statistical Plant Geography. Oxford, Clarendon. 1934.

SACRAMENTO, A.C.; ZICKEL, C.S.; ALMEIDA JR., E.B. Aspectos florísticos da vegetação de restinga no litoral de Pernambuco. Revista Árvore, v. 31, n. 6, p. 1121-1130. 2007.

SANTOS-FILHO, F.S.; ALMEIDA JR., E.B.; SOARES, C.J.R.S.; ZICKEL, C.S. Fisionomias das restingas do Delta do Parnaíba, Nordeste, Brasil. Revista Brasileira de Geografia Física, v. 3, n. 1, p. 218-227. 2010.

SANTOS-FILHO, F.S.; ALMEIDA JR., E.B.; ZICKEL, C.S. Do edaphic aspects alter vegetation structures in the Brazilian restinga? Acta Botanica Brasilica, v. 27, n. 3, p. 613 623. 2013.

SANTOS-FILHO, F.S.; ALMEIDA JR., E.B.; SOARES, C.J.R.S.; ZICKEL, C.S. Flora and woody vegetation structure in an insular area of restinga in Brazil. International Journal of Ecology And Environmental Sciences, v. 4, n. 3, p. 157-160. 2015.

SANTOS, M.; SILVA, R.S.C.; OLIVEIRA-FILHO, A.T.; CARVALHO, D. Correlações entre variáveis do solo e espécies herbáceo-arbustivas de dunas em revegetação no litoral norte da Paraíba. Cerne, v. 6, n. 1, p. 19-29. 2000.

SCARANO, F.R. Structure, function and floristic relantioships of plants communities in stressful habitats marginal to Brazilian Atlantic Rainforest. Annals of Botany, v. 90, p. 517 524. 2002.

SCARANO, F.R. Plant communities at the periphery of the Atlantic rain forest: Rare-species bias and its risks for conservation. Biological Conservation, v. 142, p. 1201-1208. 2009.

SHEPHERD, G.J. Fitopac $V$. Campinas, Universidade Estadual de Campinas - Departamento de Botânica. 2006.

SILVA, M.M.; MELO JR., J.C.F. Plasticidade da folha e lenho de cinco espécies lenhosas em duas áreas de restinga no Sul do Brasil. Iheringia, série Botânica, v. 72, n. 2, p. 173-180. 2017. 
SILVA, S.S.L.; ZICKEL, C.S.; CESTARO, L.A. Flora vascular e perfil fisionômico de uma restinga no litoral sul de Pernambuco. Acta Botanica Brasilica, v. 22, n. 4, p. 1123-1135. 2008.

SOARES JR., R.C.; ALMEIDA JR., E.B.; PESSOA, L.M.; PIMENTEL, R.M.M.; ZICKEL, C.S. Flora do estrato herbáceo em um fragmento urbano de floresta atlântica - PE. Revista de Geografia, v. 25, n. 1, p. 35-49. 2008.

TOREZAN, J.M.D. Estudo da sucessão secundária, na Floresta Ombrófila Densa Submontana, em áreas anteriormente cultivadas pelo sistema de "coivara", em Iporanga - SP. Curitiba. Dissertação de Mestrado. Setor de Ciências Biológicas, Universidade Federal do Paraná. 1995.

URIARTE, M.; BRUNA, E.M.; RUBIM, P.; ANCIÃES, M.; JONCKHEERE, I. Effects of forest fragmentation on the seedling recruitment of a tropical herb: assessing seed vs. safe-site limitation. Ecology, v. 91, n. 5, p. 1317-1328. 2010.

YADAV, A.S.; GUPTA, S.K. Effect of microenvironment and human disturbance on the diversity of herbaceous species in Sariska Tiger Project. Tropical Ecology, v. 48, p. 125-128. 2007. 